\title{
A case study of EIS development by an experienced EIS developer
}

\author{
P.A. O'Donnell, D. R. Arnott and W. Jirachiefpattana \\ Department of Information Systems, Monash University \\ Level 7, 26 Sir John Monash Drive, Caulfield East, Melbourne, 3145, \\ Australia, Phone +61 39903 2295, Fax + 6139903 2005, Email \\ peter.odonnell@is.monash.edu.au
}

\begin{abstract}
This paper describes the development of an EIS in an Australian-based subsidiary of a multinational firm. The EIS development team was lead by an experienced EIS developer seconded from the U.S.-based parent company. The structure of the EIS team and the nature of the system development process are described. Many of the problems that are normally confronted by EIS developers were avoided by the EIS team. The leader of this team was able to use his experience to ensure the smooth progression of the system development effort. The system is now the official management information source in the organisation. A survey of the system's users confirmed that the users find the system useful and the EIS team responsive to their needs.
\end{abstract}

\section{Keywords}

Developer experience, executive information systems, HOLOS, OLAP, system development

\section{INTRODUCTION}

Executive information systems (EIS) are computer based information systems that provide executives with the ability to monitor various aspects of their organisation. EIS normally provides a multi-dimensional view of data and a high quality graphical interface. The EIS data base includes extracts from the organisation's operational data base and specially acquired internal and external data. The tasks or problems that are supported by an EIS are likely to be strategic and recurring (ie they occur frequently enough and are important enough to justify the expense of EIS development).

A common theme of EIS is that the systems should be developed using a prototyping, adaptive or evolutionary approach to development (Courbon, Grajew and Tolovi 1978, Houndeshel and Watson 1987, Rockart and DeLong 1988, Wallis 1989, Paller and Laska 1990, Watson, Rainer and Chang 1991, Waston, Rainer and Frolick 1992, Fitzgerald 1992, Suvachittanont, Arnott and O'Donnell 1994). The number of development cycles becomes less frequent as development staff and users become familiar with EIS technology and the nature of the tasks they are tackling. A common observation in case study research is that the 
development staff know little about EIS when the project is initiated (Sundue 1986, Armstrong 1990, Watson 1992, Fitzgerald 1992, Watson, Rainer and Flolick 1992, Suvachittanont, Arnott and O'Donnell 1994). This is understandable when a technology is new, but EIS could now be considered a mature information technology after many years of successful systems development. The level and nature of developer experience with the process of EIS development may effect the number of evolutionary cycles, the applications developed, the speed of development, the nature of user involvement, the overall success of the system and many other aspects of the project.

Developer experience in EIS has received little research attention. This paper presents a case study of a successful EIS whose development was co-ordinated by an experienced developer/project manager who was seconded from one part of a large multi-national corporation to another.

\section{METHOD}

The case study data was collected using questionnaires and structured interviews. The purpose of using questionnaires was to obtain fundamental information about the EIS development and to generate questions for further interview. The subjects were 22 EIS users, the EIS coordinator or team leader and three EIS developers. This represents $40 \%$ of the user population and $100 \%$ of the developer population of the organisation. The users were asked about the outcomes of the EIS from both organisational and individual perspectives, the developers were questioned about the technical details of the development process, and the co-ordinator questioned on system initiation and the general nature of the development of the EIS over the life of the system. The procedure and instruments used have been used in other studies (for example Suvachittanont, Arnott and O'Donnell 1994) and is described in detail in Jirachiefpattana (1996). After the co-ordinator and developer questionnaires were analysed, detailed questions for each of the developers were designed. These questions were answered in structured interviews that ranged in length from 1 to 2 hours.

The EIS co-ordinator, whose experience in EIS development forms the focus of this study, was not one of the researchers and no special relationship existed between the EIS coordinator and the researchers. The researchers were not involved in any way in the development of the system.

\section{OVERVIEW OF THE EIS PROJECT}

The organisation that is the focus of this paper is a manufacturer and distributor of advanced office equipment. The company is a multi-national corporation based in the United States. The Australian subsidiary of the firm employs 700 people and has a network of over 300 retail dealerships. Senior management is spread across five Australian states. It has for many years been widely regarded as an innovator in the use of technology. The organisation has a corporate mission and culture strongly oriented towards the satisfaction of customer needs using a total quality philosophy.

The U.S. based parent company has had for many years a mature and well publicised EIS. The development of an EIS for use by the Australian subsidiary was initiated by that company's General Manager. Another senior manager, the Manager of Business Planning and Development, acted as the executive sponsor of the system. Both believed that important decisions about product strategies were being made without appropriate information. The information provided by the existing intensive manual reporting system was often of poor quality. The information was often not timely and some information was difficult, if not impossible to obtain. The reports produced within different organisation units often was 
contradictory. The aim of the development of the EIS was to resolve these problems and, in particular, to assist the analysis and understanding of equipment sales.

Within six months of the commencement of the EIS project the first version of the system, with 11 different screen based reports, was installed. This initial system provided information about sales revenue (within the organisation this is refered to as 'Sold Equipment Revenue'). The system sources data from the corporate billing system and other internal financial systems.

\section{STRUCTURE OF THE EIS DEVELOPMENT TEAM}

A development team of three full time information systems professionals was formed to construct the EIS. This team reports directly to the Chief Financial Officer (CFO). The team leader was seconded from the U.S. based parent company. He had previously been involved in the development of the EIS system in the U.S. and usually works in the finance arm of the firm as a decision support systems analyst. The other members of the development team, whose previous appointments were in the Information Systems Department as applications programmer and systems analyst, were recruited and appointed by the EIS team leader and the Financial Controller (who reports to the CFO). The applications programmer's major skills were in mainframe applications development. The systems analyst's major skills were database development with the Oracle system and PC applications development. The team's offices are located within the Information Systems Department. The EIS team was also, on occasion, supported by a data-base administrator from the Information Systems Department who provided advice and technical support related to the acquisition of data from existing data-base applications in the organisation.

The EIS team leader devised a structure for the control of the EIS development based upon the one used in the U.S. company. Each EIS application (the Sold Equipment Revenue is an example of an EIS application) has a official application owner and a data owner. The application owner for the Sold Equipment Revenue system is the Finance Manager. All changes to the functionality and reports of this application are approved and prioritorised by the application owner before they are handed over to the EIS development team for implementation. The data owner represents the functional area that is the major provider of the data for the EIS application. For the Sold Equipment Revenue application the data owner, a member of the finance department, helped the EIS team investigate and resolve inconsistencies and discrepancies in the source data. As a result of this formal ownership structure, relating to both the application and the source data, the EIS has obtained status as the 'official' source of data on Sold Equipment Revenue in the organisation.

\section{AN OVERVIEW OF THE SYSTEM}

The EIS was constructed using an OLAP compliant (Codd, Codd and Salley 1993) development tool called HOLOS (from Holistic Systems plc.). The server component of the software resides on an Hyundai AXIL 320 computer. The client component of the software runs on IBM compatible PCs running the Windows operating system. Each end-user's PC has approximately $8 \mathrm{mb}$ of RAM and has either a 386 or 486 based processor. The connection between the client software on the PCs and the server software on the AXIL 320 computer is made via TCP/IP over an ethernet based network.

The basis of the OLAP architecture is the ability to create multi-dimensional data structures (Frank 1995). Each item of data in a structure, or cell, represents the intersection of a number of dimensions. For example, the data stored in a cell might represent the sales of product number 1102 in the State of Victoria in the 3rd Quarter of 1995. In this case the dimensions describing the data item are product, location and time. The dimension called 


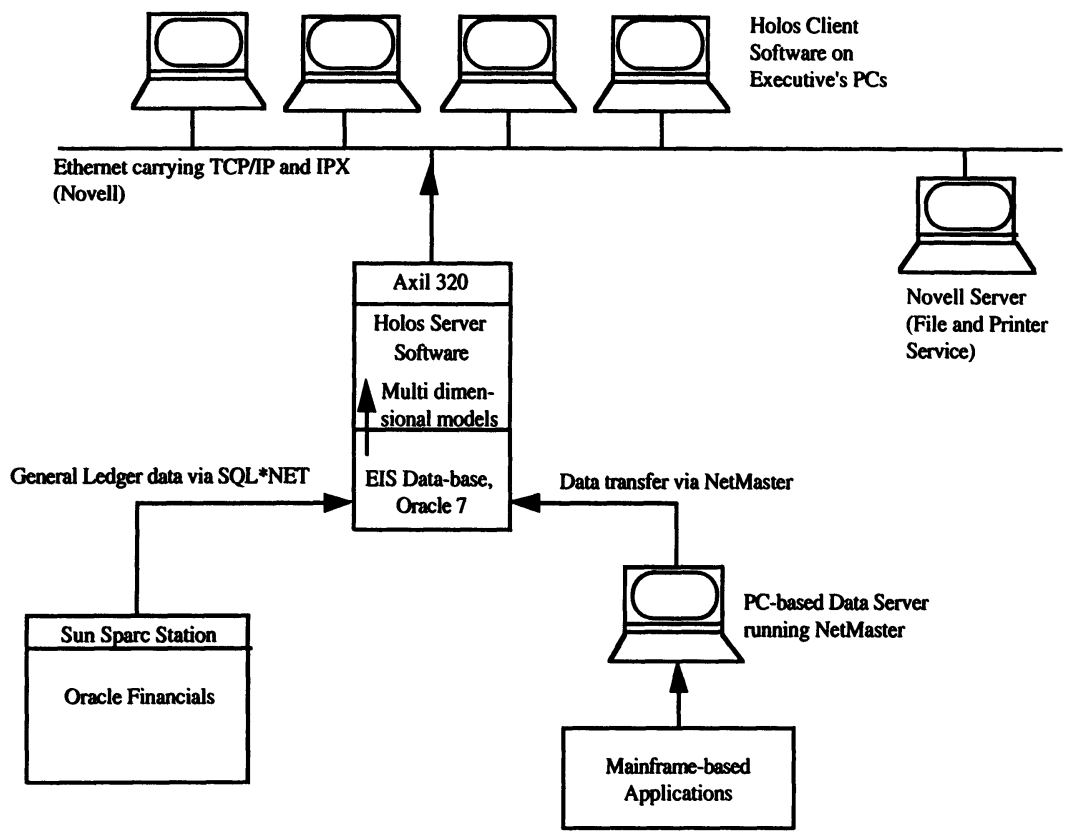

Figure 1 An overview of the architecture of the EIS.

product might contain other attributes, each representing a different product. The location dimension may contain the attributes representing other States or geographic regions. A data structure containing the dimensions of product, state and time is considered as three dimensional data and it can be viewed as any combination of these dimensions.

The data for the system is held in a relational data-base constructed using the Oracle 7 database management software. Using the terminology currently in vogue in trade-related publications on OLAP and EIS this database would be classified as a data-mart (Demarest 1994). This EIS data-base is the source of the data that populates the multi-dimensional models contained in the EIS. The HOLOS product directly queries the Oracle data-base using SQL. Until an update is required the multi-dimensional models are stored on disk on the AXIL 320 by the HOLOS system to help facilitate speedy access by end-users of the EIS. The major source of data for the EIS data-base is an existing financial system, developed using the Oracle Financials software package. Some data is also sourced from other applications running on the organisation's mainframe computer systems. The Netmaster product is used to facilitate this transfer. Figure 1 provides an overview of the architecture of the EIS. The AXIL 320 was purchased specifically for the EIS as it was felt that the capacity of the existing computer hardware could not handle the data and query processing associated with the EIS.

The initial version of the system was used by 4 senior executives, 3 middle managers and 3 other users. Currently, the number of users has increased to 55 across all levels of management as shown in Table 1 . Table 2 shows the number of users by the business units. Similarly, the number of EIS screens has increased from 11 to 60 .

The interface of the system and the reports and screens are typical of that which is expected of an EIS (Martin and Clarke 1989). The major characteristics of the EIS are the display of key performance indicators, exception reporting, the ability for users to 'drill-down' from summary reports to detailed information, color coding of reports, and a mix of graphical 
Table 1 The number of users classsified by management levels

\begin{tabular}{lr}
\hline Level of management & Number \\
\hline Top management & 10 \\
Middle management & 15 \\
Operational management & 15 \\
Other & 20 \\
Total & 55 \\
\hline
\end{tabular}

Table 2 The number of users classifed by business units

\begin{tabular}{lr}
\hline Business unit & Number \\
\hline Marketing & 20 \\
Finance & 15 \\
Personnel & 10 \\
Supplies/Service & 10 \\
Total & 55 \\
\hline
\end{tabular}

and tabular display formats. The EIS has been designed to be easy to use; the users control the system using a mouse.

The Sold Equipment Revenue application provides reports on based upon financial and non-financial information. The basic system functions are as follows:

Financial Functions

Sold Equipment Model: This model is primarily concerned with the profitability of the sold equipment. Information in the model includes equipment costs, sales revenue, cost of sales, and related overhead expenses.

Commercial Marketing Model: This model takes information from the Sold Equipment model and provides profitability analyses of the retail dealerships.

Rate Variance Reports: These examine the relationship between volume and price.

Daily Reporting Model: Presents the quantity of machines sold daily (up to the current day).

Service Model: This model shows the number of machines manufactured, associated revenues and costs, and service related labour-hours.

Cost Centre/Human Resources: This provides financial information about cost centres and other organisational divisions.

Non Financial Functions

Technical Service Model: This model enables analysis of the use of parts for the on-site service of equipment.

Stock Model: This model shows the stock levels in various warehouses.

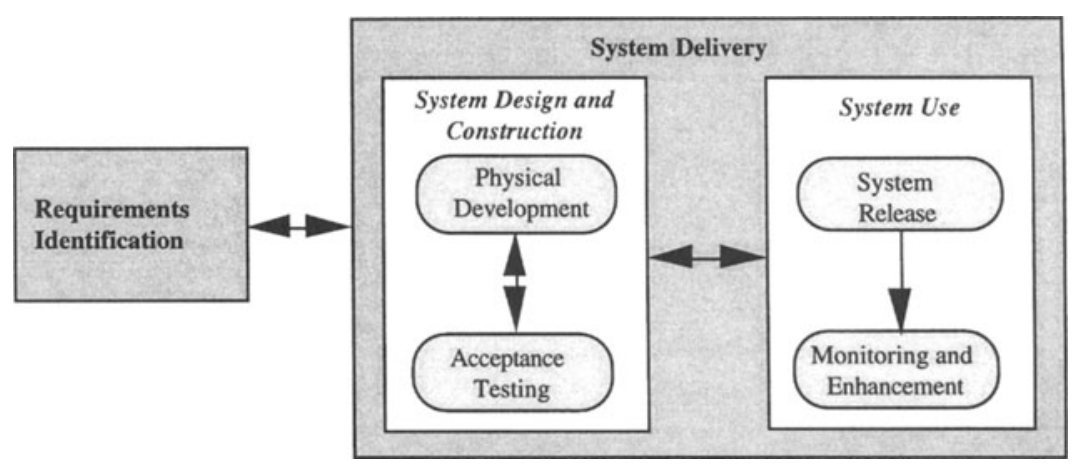

Figure 2 A Model of the System Development Process. 


\section{THE EIS DEVELOPMENT PROCESS}

The initiation phase of the system development progressed quickly. The sponsor provided direction that the first EIS application developed should be one that reported on Sold Equipment Revenue. After this decision had been made and the EIS team leader had arrived from the U.S. an informal cost/benefit analysis was undertaken. The benefits and costs of the new system were projected; the conclusion of this analysis was that development of the system would be worthwhile. The approximate start-up costs for the EIS for the hardware, software and personnel required was AUS\$ 178000,180000 and 265000 respectively. The organisation spends about $\$ 245000$ annually for on-going development, maintenance and operation of the system.

A model of the development of an EIS, changed slightly from that used by Suvachittanont, Arnott and O'Donnell (1994), is shown in Figure 2. This model can be used to explain the development of this EIS. The model contains two major phases, requirements identification and system delivery. Development activity interates between these two phases. Within the system delivery phase, there are two major activities: system design and construction, and system use. As with the major phases, the development activity iterates between these two actitives. Table 4 provides a summary of the major tasks, information required, methods used and people involved during each of the development activities.

\subsection{Requirements identification}

The functionality required in the system was directly determined by the users. They created their own high-level requirements and then provided a requirements specification document to the EIS team. This requirements specification was mostly a set of reports which the users would like to receive. After formal approval of the specification by the application owner the EIS development team undertook the following tasks:

Data Analysis. The EIS team analysed the reports presented in the specification. The users were consulted to help to clarify what data was actually required to produce the reports.

Information Identification. The EIS team, in consultation with the data-base administrator attempted to identify sources for the required data.

Software Selection. The EIS team leader decided, that in order to facilitate timely system delivery, an EIS development tool would be required. A formal package selection process was followed before the HOLOS system was chosen. The formal assessment involved identifying and weighting the required package attributes, identifying candidate tools and then evaluating each tool according to the desired attributes. Table 3 shows the criteria used for the selection of the EIS development tool. It is interesting to note that the tool selected for the project is different to that used for EIS development in the parent company.

\subsection{System design and construction}

The system design and construction activity comprises two further sub-activities: physical development and acceptance testing.

Phyiscal Development. The physical development activitity consisted of two further subtasks, the construction of the EIS data-base and the construction of the EIS itself. The data administrator from the IS Department constructed data loading routines using the IDEAL language. The Oracle EIS database was created to hold this data. The Finance department has responsibility for ensuring that current data is up-loaded into the system when available. Mostly new data becomes available on a monthly basis. However, this does vary from time to time so the data update is initiated manually rather than by some automatic method. 
Table 3 Criteria used for EIS package selection

\begin{tabular}{ll}
\hline Category & Criteria \\
\hline External product support & Supplier expertise \\
& User base \\
& Availability of expertise \\
Development/maintenance & Quick and easy development \\
& Separation of data and logic \\
Value for money & Up front cost \\
& On-going cost \\
System environment & Novel compatible \\
& Windows compatible \\
Product features & High speed \\
& Drill-down capability \\
\hline
\end{tabular}

The initial task faced by the development team in actually coding the system was to learn how to develop applications using the HOLOS system. After the team underwent basic HOLOS training a prototype system was constructed. This prototype served three purposes: to help the team further develop their HOLOS coding skills, to confirm the teams understanding of the user's requirements and to test a proposed standard format for on-screen reports. It had been decided that a standard format for each the interface was required to help provide a consistent and easily understood system. For example this standard included rules for the use of on-screen colours. The background to each screen was grey. Any number could be double clicked to provide more detail. Colour coding was used to highlight exceptions. Numbers in a range that indicated poor performance were coloured red whilst black or green was used for good numbers.

Acceptance Testing. Once the prototype system was made available to users an acceptance testing programe was undertaken. This testing ensured that the system performed its functions in an acceptable manner and also that the data presented were accurate. Interviews of key users were used to collect information during this phase.

\subsection{System use}

The system use phase consists of the release of the system to user community and then the ongoing maintenance and enhancement of the system.

System Release: After the initial prototype had been modified in light of the feedback obtained as a result of the acceptance testing phase the system was released for use by the wider user community. The numbers of users of the system increased dramatically. The EIS team employed with each new user individual one-to-one training of about one hour duration to make sure that the users understood the basic principles of the system. To train new users in the future, the EIS team has plans to train a group of around 8 specially selected users who will be responsible for the basic training of new users.

To assist users of the system a help function has been included. When users require an explanation of how to use one of the functions of the system, they can activate this function and get (at least) some of the information that they require. A paper-based document describing the use of the system from the user's perspective has been developed by the application owner.

Monitoring and Evaluation: The purpose of this activitiy is to monitor use of the system and identify changes that are required. To implement the identified changes the devlopment process cycles back to the system design and construction activity. 
Table 4 Summary of the characteristics of the EIS development process

\begin{tabular}{|c|c|c|c|c|c|}
\hline Activities & Major tasks & $\begin{array}{l}\text { Required } \\
\text { information }\end{array}$ & $\begin{array}{l}\text { Methods } \\
\text { techniques/ } \\
\text { tools }\end{array}$ & Deliverables & People involved \\
\hline $\begin{array}{l}\text { Requirement } \\
\text { Analysis }\end{array}$ & $\begin{array}{l}\text { - Data analysis } \\
\text { - Information } \\
\text { identification } \\
\text { - Software } \\
\text { selection }\end{array}$ & $\begin{array}{l}\text { User needs } \\
\text { - Information } \\
\text { about desir- } \\
\text { ed functions } \\
\text { - Timing of } \\
\text { data } \\
\text { - Features of } \\
\text { software }\end{array}$ & $\begin{array}{l}\text { Interview } \\
\text { - Critical } \\
\text { success } \\
\text { factors } \\
\text { - Prototyping } \\
\text { - Discussion } \\
\text { with } \\
\text { support } \\
\text { personnel }\end{array}$ & $\begin{array}{l}\text { - Functional } \\
\text { specificat- } \\
\text { ion }\end{array}$ & $\begin{array}{l}\text { - Functional } \\
\text { area } \\
\text { management } \\
\text { - Programmers } \\
\text { - Data } \\
\text { Providers }\end{array}$ \\
\hline $\begin{array}{l}\text { System } \\
\text { Development }\end{array}$ & $\begin{array}{l}\text { - Language } \\
\text { training } \\
\text { - Model } \\
\text { specification } \\
\text { development } \\
\text { - Functionality } \\
\text { coding } \\
\text { - Database } \\
\text { development } \\
\text { - Data loading }\end{array}$ & $\begin{array}{l}\text { - Functional } \\
\text { specification }\end{array}$ & $\begin{array}{l}\text { - Prototyping } \\
\text { - HOLOS } \\
\text { - Oracle } \\
\text { - MS-Access } \\
\text { - System } \\
\text { flow chart } \\
\text { - Normalisa- } \\
\text { tion } \\
\text { - Data flow } \\
\text { diagrams } \\
\text { - Decision } \\
\text { Trees } \\
\text { - Pseudocode }\end{array}$ & $\begin{array}{l}\text { - Prototype } \\
\text { model } \\
\text { - 1st release } \\
\text { model }\end{array}$ & $\begin{array}{l}\text { - Programmers } \\
\text { - Vendor }\end{array}$ \\
\hline $\begin{array}{l}\text { Acceptance } \\
\text { Testing }\end{array}$ & $\begin{array}{l}\text { - System } \\
\text { testing } \\
\text { - System } \\
\text { modification }\end{array}$ & $\begin{array}{l}\text { - User } \\
\text { feedback }\end{array}$ & - Interview & $\begin{array}{l}\text { Final } \\
\text { model }\end{array}$ & $\begin{array}{l}\text { - Programmers } \\
\text { - Functional } \\
\text { users }\end{array}$ \\
\hline $\begin{array}{l}\text { System } \\
\text { Release }\end{array}$ & $\begin{array}{l}\text { - System } \\
\text { installation } \\
\text { - Training }\end{array}$ & & $\begin{array}{l}\text { One on one } \\
\text { training }\end{array}$ & $\begin{array}{l}\text { Interactive } \\
\text { help }\end{array}$ & $\begin{array}{l}\text { - Programmers } \\
\text { - Functional } \\
\text { users }\end{array}$ \\
\hline $\begin{array}{l}\text { System } \\
\text { Maint- } \\
\text { enance and } \\
\text { Enhancement }\end{array}$ & $\begin{array}{l}\text { - Functionality } \\
\text { Improvement }\end{array}$ & $\begin{array}{l}\text { User } \\
\text { feedback }\end{array}$ & & $\begin{array}{l}\text { Enhanced } \\
\text { system }\end{array}$ & $\begin{array}{l}\text { - Programmers } \\
\text { - Functional } \\
\text { users }\end{array}$ \\
\hline
\end{tabular}

Once the system was available to the wider user community, requests for changes and extra functions were received by the EIS team. There were two causes for these requests. One was that with experience, the users came to a better understanding of what the system could do. They were able to understand and describe functions and reports that the system could provide that would be of use to them. Further, as the system was released it obtained status as the 'official' source of information within the organisation. As a result of this 'official' status, changes to the organisation's operations or changing environmental conditions, necessitate (often urgent) changes to the system.

Each system modification request has to be authorised by the EIS owner, the Financial Planning manager. He considers each enhancement request and determines its relevance and importance. Prioritorised approved requests are passed onto the EIS team who them work to incorporate the requested change within the system by cycling back to the system design and construction activity. 
Table 5 The difficulty of activities related to system development

\begin{tabular}{lccc} 
& Avg. Score & SD. & Range \\
\hline Activity & 3.33 & 0.58 & $3-4$ \\
Identifing executive requirements & 2.67 & 1.15 & $2-4$ \\
Identifying data & 3.33 & 1.15 & $2-4$ \\
Sourcing data & 2.33 & 0.58 & $2-3$ \\
Desigining the system & 2.33 & 0.58 & $2-3$ \\
Constructing the system & 4.33 & 1.15 & $3-5$ \\
Getting feedback from the users & & & \\
\hline
\end{tabular}

To help monitor the performance and use of the EIS, a monitoring system was developed and added to the system. This monitoring system records information such as how many modules were loaded, which reports were retrieved and how often, and how many people used the EIS. This information has allowed the EIS owner and the development team to remove some unused modules from the system.

\section{THE DEVELOPERS' VIEW OF THE DEVELOPMENT PROCESS}

In order to better understand the EIS team's feelings about the development of the system, a simple questionnaire was administered to identify the difficulty associated with various activities during the system development. As previously noted, the questionnaire used is the same as used by Suvachittanont, Arnott and O'Donnell (1994). The questions were answered using a scale which ranged from 1 (not difficult) to 5 (very difficult) for each activity specified in the questionnaire. Table 5 presents the mean score, standard deviation (SD) and the range of the responses of the 3 members of the EIS team. The results show that in general, the developers thought that EIS implementation was of reasonable difficulty as the average scores of identifying requirements and data, getting the data, designing and constructing the system is less than 3.5. This indicates that the development, from the perspective of the developers, progressed smoothly.

The only aspect of system development that the developers indicated that they had difficulty was obtaining feedback from users. The developers related that once users had seen the system they were inundated with requests for changes and other feedback.

\section{THE USERS' VIEWS OF THE SYSTEM}

\subsection{Measurement technique}

In order to obtain some insight into users' feeling about the system a questionnaire was administered to the system's users. The short questionnaire presented the users with a series of statements. They responded to each of the statements using a 5-point Likert scale. A response of 1 meant that the user thought that the statement was incorrect in regard to their perception of the system while a response of 5 represented very high agreement. For each statement, an average score below 3.0 indicated that the respondents disagree more than agree with the statement about the EIS. As previously noted, the relevance of each statement can be related to trends identified in the general EIS literature and is discussed in Suvachittanont, Arnott and O'Donnell (1994) and Jirachiefpattana (1996).

The executive user questionnaire was sent to 60 users and $22(36.67 \%)$ were returned. Table 6 shows the managerial level of the respondents. More than $27 \%$ of the returned questionnaires were completed by the most senior management of the organisation. This 
Table 6 Distribution of respondents by position

\begin{tabular}{lrr} 
Position & Number & $\%$ \\
\hline Senior mgt. & 6 & 27.27 \\
Middle mgt. & 8 & 36.36 \\
Operational mgt. & 3 & 13.63 \\
Others & 5 & 22.73 \\
Total & 22 & 100 \\
\hline
\end{tabular}

Table 7 Distribution of respondents by business unit

\begin{tabular}{lr} 
Business unit & Number \\
\hline Marketing & 12 \\
Finance & 7 \\
Supplies/Service & 3 \\
Total & 22 \\
\hline
\end{tabular}

Table 8 Period of working in the organisation

\begin{tabular}{lr} 
Years & Number \\
\hline $0-5$ & 6 \\
$5-10$ & 4 \\
$10-15$ & 3 \\
$15-20$ & 7 \\
$20+$ & 2 \\
Total & 22 \\
\hline
\end{tabular}

indicates that, whilst the system is the official source of information in the organisation and as such is used by managers of all levels that it also has a significant number of executive users. Table 7 presents the distribution of the respondents by business units. The highest number of the subjects came from Marketing area. The length of time that of subjects had worked for the organisation ranged from 1 to 23 years as shown in Table 8 .

\subsection{Primary Purpose of Using the EIS}

The primary purposes of using the system were categorised into five groups as illustrated in Table 9. The functional area most frequently addressed by the EIS use was Finance. Here the users accessed the EIS to obtain information about profitability, revenue of various products and cost centres.

Table 10 shows the distribution of the period that users have used the EIS. The majority of the subjects have used the system less than 2 years. The mean time of each user spent using the EIS per day was 50.24 minutes. (Note that the distribution shown in Table 10 the

Table 9 Primary purpose of using the EIS

Sales Sales results/Monitoring/Analysis

Product performance

Order and installation tracking

Identifiying areas of concern

Finance Costs of Centres/Sales/Services/Products

Budget Information/Tracking/Trend

Revenue and trends

Profitability analysis

Margin movement/Analysis

Actual spending vrs. budget analysis

Forecast/Plan comparision

Financial figure monitoring

Overall managment

Business performance/Planning

Problem analysis

Planning and control

Identifying areas of opportunity

Management decision

Customer service

Other Data extraction 
Table 10 Period of time using the EIS

\begin{tabular}{lr}
\hline Year & Number \\
\hline $0-2$ & 14 \\
$2-4$ & 5 \\
$4+$ & 3 \\
Total & 22 \\
\hline
\end{tabular}

Table 11 Time spent on the EIS per day

\begin{tabular}{lr} 
Minutes & Number \\
\hline $0-15$ & 2 \\
$15-30$ & 9 \\
$30-45$ & 0 \\
$45-60$ & 7 \\
$60+$ & 3 \\
Total & 22 \\
\hline
\end{tabular}

calculation of the mean time spent on the EIS per day excluded one response for which the answer was 1 day.) Table 11 presents the distribution of time spent on the EIS, which varies from 5 to 150 minutes per day.

\subsection{Organisational Success}

The seven organisational satisfaction measures are shown in Table 12. The total average score was 25.59 out of $35(73.11 \%)$. This score indicates that the users were relatively appreciative of the way that the system supports their work. In general, most measures received high scores which supported the trend observed in the general literature. Only the average score of decreasing paper flow was lower than 3.0.

Table 12 Mean scores and standard deviations for the organisational satisfaction measures

\begin{tabular}{lcl}
\multicolumn{1}{c}{ Measure } & Avg. Score & $S D$. \\
\hline Important to the organisation & 4.36 & 0.79 \\
Improve the planning process & 4.09 & 0.75 \\
Improve organisational communication & 4.00 & 0.53 \\
Improve operational control process & 3.82 & 1.05 \\
Gain commitment of all managers & 3.41 & 0.80 \\
Improve the image of the IS. Department & 3.18 & 1.05 \\
Decrease paper flow & 2.73 & 1.12 \\
\hline
\end{tabular}

Table 13 Mean scores and standard deviations for the individual satisfaction measures

\begin{tabular}{lcc}
\hline \multicolumn{1}{c}{ Measure } & Avg. Score & $S D$. \\
\hline Save time & 4.14 & 0.83 \\
Can do more & 4.05 & 1.09 \\
Easier to obtaining information & 3.82 & 1.00 \\
Quicker decision making & 3.82 & 1.14 \\
Better decision making & 3.77 & 0.87 \\
Rely on the EIS & 3.59 & 0.96 \\
Improve thinking about problems & 3.45 & 1.22 \\
Gain more knowledge about IT & 3.00 & 1.23 \\
User involvement in development & 2.36 & 1.47 \\
\hline
\end{tabular}




\subsection{Individual Success}

The measures of individual satisfaction are shown in Table 13. In supporting individual users work, the EIS can be considered relatively successful with a total average score of 32.0 from $45(71.11 \%)$. The measures that received an average score less than 3 were most interesting as they indicate potential problem areas for this EIS, particiularly "user involvement in development" at 2.36. However, its standard deviation was relatively high (1.47) meaning that there is little consensus among the subjects about the correctness of the statement.

Even though the average score of the EIS facilitating quicker decisions was high (3.82), there was little consensus among users (SD. 1.14). In contrast, there was relatively high consensus about "making better decisions" and "relying on the EIS".

Further insight into the relatively high success rating of this EIS from both the organisational and user perspectives can be gained from unprompted comments about the EIS in general. These comments are produced verbatim in Table 14.

\section{CONCLUDING DISCUSSION}

The culture of the corporation in this case study is such that executives expected and wanted to use an EIS, in contrast to other EIS development environments where a significant level of user resistance is encountered. The EIS team leader's experience and skills in dealing with executive users helped, no doubt, to ensure that this positive attitude was made to contribute to the success of the system development. Specification of the information requirements of executive users is often considered to be one of the most difficult aspects of EIS development. However, in this case a formal project structure created by the team leader, gave ownership of the requirements definition aspects of the system development to a representative from the user community. This helped to ensure that the initial prototype of the EIS system was useable and performed functions of use and interest to the wider user community. Once the system was installed and users trained they were able to envisage extra functions and reports that the system could produce that would help them in their work. The now mature system has entered and ongoing cycle of maintenance and refinement. It will be important for the developers, if the system is to remain successful, to be able to correctly interpret and also to keep up with these user requests for changes.

Many other problems that are normally confronted by inexperienced EIS developers were avoided by the EIS team. The leader of this team was able to ensure the smooth progression of the system development effort. He ensured that a formal package selection process was undertaken to select an appropriate development platform. An OLAP tool, called HOLOS was chosen. IS professionals when they first use a complex multi-dimensional modelling tool like HOLOS face a steep learning curve and are unproductive for a long period of time while they learn to use the tool to full advantage. In this case the team leader ensured that all the members of the development team were full trained in EIS development with the HOLOS tool. This allowed full advantage to be taken of the flexible modelling and reporting facilities offered by the OLAP architecture.

The EIS team leader has now returned to the U.S. This has not had any adverse effect on the ongoing performance of the system. The remaining members of the development team are now quite expeirenced at working with executive level users and have the required technical skills to continue to enhance and refine the system.

That the system achieved status as the 'official' data source in the corporation was due in part to the willingness of the executives to accept it. However, no matter how willing the user community was to want to use the system as a supply of information, if the data the system reported was inaccurate, untimely or unreliable the EIS would not have retained its status. 
Table 14 General comments about the EIS

- Empowerment relies on information - the real facts. They made a great decision when EIS was put in - Total support from me.

- We are firstly to browse-put an issue and then quite quickly analyse the issue-it necessary down \& transaction level. Also resolve a lot of disputes- the general rule is that "the system is right". In this way if the system is helps people identify the causes quickly

- The EIS is new and is a customised package. It will evolve into what it should be as it must be a base system by its introductory nature. As deficiencies are found, its performance value will increase. However, it is the first adjustable management microscope useable by individual managers and as such has encouraged previously unseen corporate views.

- Ability to analyse problems from different angles to test assumptions; What if analysis; Developing monitoring mechanisms for approved capital spend/ process changes; Early identification of problems.

- The EIS at this company is still in relative early stage of development. Certain 'modules' are complete and have been available for up to 2 years. However, other modules still in development.

- [The]'EIS' has given all of us much needed fact based data. It is not yet totally perfect but it's also helping us identify the imperfections in our base systems. [The EIS] is only as good as the base data.

- EIS is a continuous process. In a dynamic market place, such as information technology and communications, accurate and timely information is critical, EIS must enable managers to deliver to the market they are targeting with effective communication i.e. market share etc. EIS should be able to be able to be updated easily and keep pace with a dynamic environment, that is present in so many businesses today.

- The effectiveness of EIS is a function of the other systems which are feeding it with information. If EIS is fully integrated at the planning stage to other front-end systems, it will provide the greatest benefits. When EIS has to depend on obsolete system for data, its usefulness is very low.

- Most companies and myself struggle with EIS and DSS. Where should we implement these systems, what level of information should be available. Ultimately, the user will drive the implementation and deployment. However, the IS department must drive the first stages and show what can be done.

- The existence of SQL tables used to feed the HOLOS structures has tangible benefits on the other aspects of accounting work. I recommend that more of our accounting staff learn to write SQL "Select" statements and use SQLLOAD to facilitate their work.

In summary, the positive attitude toward the EIS project from the executive user community along with the skills and leadership of the EIS team leader contributed significantly to the success of this system. Studies of EIS development often disregard these aspects of system development. Future research into EIS should investigate the relationship between the culture and expectations of the executive users and the experience and skill of the development team as they are likely to be major determinants of success and failure in other EIS developments. 


\section{REFERENCES}

Armstrong, D. (1990). 'How Rockwell Launched Its EIS'. Datamation, 30:8, $69-72$ (Mar.). Codd, E.F., S.B. Codd, and C.T. Salley. (1993) Providing OLAP to User-Analysts: An IT Mandate. E.F.Codd \& Associates.

Courbon, J.C., Grajew J. and Tolovi J. (1978) 'Design and Implementation of Interactive Decision Support Systems' Institute d'Aminisittarion des Enterprises, Grenoble, France: Unpublished.

Demarest, M. (1994) 'Building the data mart' DBMS: Database and Client/Server Solutions 7:8 (July), pp 44-52, 71 .

Frank, M. (1995) 'A Drill-Down Analysis of Multi-Dimenional Databases' DBMS: Database and Client/Server Solutions 7:8 (July), pp60-71

Fitzgerald, G. (1994). 'Outsourcing of IT in the United Kingdom: A Legitimate Strategic Option?' Proceedings: 5th Australasian Conference on Information Systems, (eds.) Graeme Shanks and David Arnott. Monash University, 27-40.

Houdeshel, G. and Watson, H.J. (1987). 'The Management Information and Decision Support (MIDS) System at Lockheed-Georgia' Executive Information Systems: Emergence - Development - Impact, (eds.) Watson, J. Hugh; Rainer, Kelly R.; Houdeshel, George. New York: John Wiley \& Sons. 13-31.

Jirachiefpattana, W. (1996) Methdological Issues in EIS Development in Australia and Thailand: A Case Study Approach Unpublished PhD Thesis. Department of Information Systems, Monash University, Melbourne, Australia.

Paller, A. and Laska, R. (1990). The EIS Book: Information Systems for Top Managers.. Illinois: Dow Jones-Irwin.

Rockart, J.F. and DeLong, D.W. (1988). Executive Support Systems: The Emergence of Top Management Computer Use.. Illinois: Dow Jones-Irwin.

Sundue, D.G. (1990). 'GenRad's On-Line Executives' Management Information Systems: Readings and Cases- A Managerial Perspective, (eds.) Boynton, C. Andrew; Zmud, W. Robert. Glenview, Illinois: Scott, Foresman. 162-170.

Suvachittanont W., D.R. Arnott and P.A. O'Donnell (1994) 'Adaptive Development in Executive Information Systems : A Manufacturing Case Study'. Journal of Decision Systems, 3:4.

Watson, H.J. (1992). 'How to Fit an EIS into a Competitive Context'. Information Strategy: The Executive's Journal, 8:2, 5-10 (Winter).

Watson, H.J. Rainer Jr., R.K. and Koh E. Chang (1991). 'Executive Information Systems: A Framework for Development and a Survey of Current Practices'. MIS Quarterly, 15:1, 13-30 (March).

Watson, H.J.; Rainer Jr., R.K. and Frolick, M.N. (1992). 'Executive Information Systems: An Ongoing Study of Current Practices'. International Information Systems, 1:2, 37-56 (Apr.).

Wallis, L. (1989). 'Power Computing at the Top' Executive Information Systems: Emergence - Development • Impact, (eds.) Watson, J. Hugh; Rainer, Kelly R.; Houdeshel, George. New York: John Wiley \& Sons. 301-314.

\section{BIOGRAPHY}

\section{Mr Peter A. O'Donnell}

Peter O'Donnell is a Lecturer in Information Systems at Monash University. He received a Bachelor of Applied Science from the Ballarat College of Advanced Education and a Master's of Computing from Monash University. His current research interests include the design of multi-dimensional data structures and the use of influence diagrams in decision support. 


\section{Professor David R. Arnott}

Professor David R. Arnott is the Head of Department of Information Systems at Monash University. $\mathrm{He}$ is also Associate Dean of the Faculty of Computing and Information Technology. Professor Arnott commenced his computing career in 1970 and worked during the 1970's as a systems analyst and consultant, specialising in the support of management rather than the automation of clerical processes. He became an academic in 1980. Professor Arnott's teaching area is the managerial use of information systems, and his principal research area is the use of psychological theories of human judgement in the development of decision support systems.

\section{Ms Waraporn Jiracheifpattana}

Ms Waraporn Jiracheifpattana (nee Suvachittanont) is a doctoral candidate in the Department of Information Systems at Monash University, Australia. before she commenced her $\mathrm{PhD}$ program, she worked as a system analyst at the Information Institution for Education and Development (IPIED), Thammasat University, Thailand. her major works include the creation of the Provincial Management Information System and the Departmental Management Information System which assists government officers allocate budget to villages. As well, she has worked as a researcher to develop Human Development Indicators under United Nations sponsorship. 